\title{
European Microbeam Analysis Society Holds First International Workshop
}

The European Microbeam Analysis Society (EMAS) held its first international workshop March 8-10, 1989 in Antwerp, Belgium. Founded in 1987, the society's membership comprises practitioners of microbeam analysis techniques using electrons, ions, lasers, etc. The first workshop was dedicated to quantitative electronprobe $x$-ray microanalysis with a special session on electron energy loss spectroscopy (EELS).

Godfied Roomans (University of Uppsala) introduced the first subject, specimen preparation, showing that, particularly in the biosciences, the application of cryo methods is attracting much attention.

In discussing actual $x$-ray microanalysis, Peter Karduck (Gemeinschaftslabor für Elektronenmikroskopie der RWTHAachen) showed several (sometimes ignored) effects that analytical conditions and instrument factors have on the K-ratio measurements. He further showed the actual penetration of beam electrons in matter and the depth distribution of x-ray generation based on a Monte Carlo program.

Regarding quantitation, Victor Scott (University of Bath) summarized a number of mathematical expressions for the $\varnothing(\rho \mathrm{z})$ curves now used to fit the real situation. In fact, it appears that much of the physics has been thrown overboard in favor of empirical approaches. This led to an interesting fundamental discussion among the attendees.

In considering light-element analysis, Guillaume Bastin (University of Eindhoven) showed that reliable measurements are now possible for elements like $B$, $C, N$ and $O$, but that care is needed in choosing the standard. On the other hand, a very low accelerating voltage in order to minimize the matrix effects, is no longer a hard condition for performing an accurate analysis.

Pierre Trebbia (University of Orsay) decribed another type of electron microbeam analysis, electron energy loss spectroscopy, and he pictured a rapidly developing part of science which is powerful in both sensitivity and resolution.

On the last day Jean-Louis Pouchou (ONERA-Chatillon) showed a complicated but well-defined special form of quantitation called thin-layer analysis, which is not to be confused with the thin-section analysis in biology. He showed that in certain cases it is possible to analyze both the thickness and the composition of different layers in one sample.

Claude Le Gressus (CEN-Saclay) ended the session with an exciting talk on charging, showing the audience that if you cannot eliminate this phenomena completely you'd better make some analytical use of it.

The afternoons were totally reserved for discussions (plenary, roundtable, and informal). This experiment was quite successful. In some cases the audience kept asking questions even after three hours, in contrast with other meetings where often only limited time is reserved for discussions.

The first meeting of the EMAS was thoroughly organized and the outcome was highly successful, especially thanks to the excellent local coordination provided by Gijbels and Luc Van 't dack (both University of Antwerp) who did an excellent job. Some 150 attendees, more than 20 poster contributions, and 9 exhibitors all assembled in a scenic, restored ancient monastery-hospital now equipped as Congress Centre't Elzenveld, in the heart of Antwerp.

EMAS will continue with this workshop formula, meeting every two years in the spring somewhere in Europe. The next workshop, scheduled for Dubrovnik, Yugoslavia in 1991, will expand the program somewhat to include electron-probe microanalysis, EELS, and Auger electron spectroscopy.

Abraham Boekestein EMAS President TFDL-Wageningen

\section{7th International Conference on Ion Beam Modification of Materials}

\author{
Knoxville, Tennessee September 9-14,1990
}

\begin{abstract}
Sponsored by Oak Ridge National Laboratory; cosponsored by the Materials Research Society. For information contact: IBMM'90, Oak Ridge National Laboratory, PO Box 2008, MS 6033, Oak Ridge, TN 37831-6033; fax (615) 574-4143. This conference will bring together investigators of ion beam modification of materials to discuss ion-solid interactions; ion beam processing of metals, semiconductors, and insulators; ion beam mixing; and novel techniques and applications.

Related Conference - The Second International Conference on Electronic Materials (IECM-II), cosponsored by MRS, the Japan Society of Applied Physics, and E-MRS, will be held September 17- 19, 1990 in Hoboken, New Jersey, immediately following the IBMM Conference. For information on ICEM-II, contact J. Stokes, Materials Research Society, 9800 McKnight Road, Pittsburgh, PA 15237; telephone (412) 367-3003; fax (412) 367-4373.
\end{abstract}

